Professor Mohammed Omar Sohaibani that appeared in the Volume 13, Number 3, 1993 issue of the Annals of Saudi Medicine 1993;13:213-4.

The historic and contemporary points which Professor Sohaibani makes about the value to autopsies in medicine are well taken. In this context, readers may wish to look back on an Editorial on the same topic entitled Autopsies, Medicine, and the Public that appeared in the Annals, Volume 8 , Number 5,1988 . It is important to note that in the intervening five years or so, a number of Saudi trainees in pathology have completed extensive studies of autopsies in major departments of pathology overseas, in particular in Australia. While one of the objectives of this experience is to meet training requirements towards Fellowship in the Royal College of Pathologists of Australasia, the more important aspect is, as envisaged several years ago, that there is a developing cadre of Saudi medical graduates trained in pathology to whom the importance of autopsies is self evident.

It is to be hoped that as these well-trained young Saudi consultant pathologists take up appropriate specialist positions in pathology in the Kingdom, autopsies will become a part of the day-to-day scene in major hospitals and medical schools in Saudi Arabia.

Mortui vivos docent: let the dead teach the living

Peter B. Herdson, MB, ChB, B Med Sc, PhD,

FRCPA, (Hon)FRACR

Professor and Director

ACT Pathology

Woden Valley Hospital

P.O. Box 11

Woden, Canberra ACT 2605

Australia

\title{
Autopsies in Saudi Arabia
}

To the Editor: I was delighted to read the Editorial entitled Autopsies and Medicine in Saudi Arabia by Associate 